\title{
IMPACT OF TEMPERATURE ON THE STABILITY OF SILKWORM COCOON FIBERS
}

\author{
Bruno Luís Sacco a e Henrique de Santana*,a, (1) \\ aDepartamento de Química, Centro de Ciências Exatas, Universidade Estadual de Londrina, 86051-990 Londrina - PR, Brasil
}

Recebido em 16/02/2019; aceito em 12/06/2019; publicado na web em 18/09/2019

\begin{abstract}
In this study raw and processed silkworm (Bombyx mori) cocoons were investigated using confocal Raman spectroscopy in conjunction with differential scanning calorimetry (DSC) in order to examine the effect of temperature on the molecular conformation of silk fiber structures. Using DSC, a broad endothermic curve was observed at moderate temperatures, shedding light on the vaporization of both raw and processed cocoons, a phenomenon that could also indicate a strong interaction between silk fibroin and water molecules. Over the temperature range set for this study, Raman spectra of raw and processed cocoons were compared at different excitation radiations after drying both kinds of cocoon in an oven at 80 and $125^{\circ} \mathrm{C}$ for 60 minutes. By correlating the intensity ratios of the deconvoluted Raman bands using the broad bands characteristic of amide I and III, it was possible to evaluate the conformational changes in both materials. At excitation radiation of $532 \mathrm{~nm}$, the deconvoluted Raman spectra for the amide III band indicated that, for both samples, there was a reduction in $\beta$-sheet conformation compared to $\alpha$-helix conformation, and this structural disruption was driven by increased temperature. At radiation of $785 \mathrm{~nm}$, the bands attributed to amino acid residues in the side chains increased in intensity, and by deconvoluting the amide I band, increased temperature was found to induce a transition from $\beta$-sheets to $\beta$-turns in both materials.
\end{abstract}

Keywords: silk fibroin; Raman spectroscopy; Bombyx mori; silkworm cocoons; molecular conformation.

\section{INTRODUCTION}

The larvae of Bombyx mori (B. mori) are responsible for a significant portion of the global production of silk, ${ }^{1}$ a material used mainly in the textile industry. ${ }^{2}$ The silkworm cocoon comprises two proteins: $70-80 \%$ silk fibroin (SF) and 30-20\% sericin, with residual contaminating fractions of 1-2\%, including waxes and ash, pigments, sugars and other impurities. ${ }^{3,4}$ Sericin is a hydrophilic protein $^{2}$ unifying and enwrapping the SF filaments to form the cocoon structure. ${ }^{5,6} \mathrm{SF}$ is a hydrophobic bipolymer, ${ }^{3}$ comprising two highly organized regions: the crystalline part providing mechanical strength and the amorphous part conferring elasticity and flexibility. ${ }^{7,8}$

The primary structure of the silk fibers is made up of a sequence of amino acids that form the polypeptide chain, determining the shapes that these chains assume. ${ }^{9}$ The intermolecular structures are formed by hydrogen bonds in a sheet-like array. ${ }^{10}$ The conformation of the polypeptide chains are further elucidated in the work of Lefèvre, et al. ${ }^{11}$ who used polarized Raman microspectroscopy to show the molecular organization of the silk produced by $B$. mori, with a combination of different quantities of $\beta$-sheets and flexible structures ( $\beta$-turns and $\alpha$-helical structures).

A study of the structural stability of these materials is warranted since the silk filament industrialization process is multi-stage, and some stages involve subjecting the cocoon to moderately high temperatures. One of these stages is cocoon drying prior to the transformation of the pupae into moths, conserving filament quality. Drying begins at a temperature of 125 to $130{ }^{\circ} \mathrm{C}$, interrupting the life cycle of the living pupae inside the raw cocoon. Drying sessions vary in terms of temperature, which is gradually lowered as the process continues. The drying time is between 6 and 7 hours and the final temperature is around $40^{\circ} \mathrm{C}$. After drying, the cocoons are stored for at least two weeks to allow the sericin to completely stabilize. In the processing stage, the cocoons are pressure-cooked in hot water to soften the sericin gum, facilitating the unwinding operation and improving the shine and texture of the fabric. ${ }^{2}$

This study investigates the effect of temperature on the structural organization of raw and processed cocoons, with the aim of better understanding the properties of this material. Thermal analysis and Raman spectroscopy resources were used to characterize the arrangement of the segments in the polypeptide-generating matrices forming the cocoon. The results show that temperature plays a crucial role in determining the nature of SF secondary structures.

\section{EXPERIMENTAL}

\section{Materials}

The cocoons of the silkworm (B. mori) used in this study were supplied by Empresa Bratac de Fiação de Seda, based in Londrina, Paraná State, Brazil.

\section{Cocoon classification}

The cocoon samples were initially classified as raw cocoons, prior to any heat treatment, and processed cocoons, after heat treatment in drying ovens. Raw and processed cocoons were subsequently cut into 0.5 x $0.5 \mathrm{~cm}$ pieces using stainless steel scissors.

\section{Cocoon oven drying}

Once the cocoons had been classified, they were subjected to two different drying programs in an oven (FANEN, Modelo $3015 \mathrm{SE}$ ), at 80 and $125^{\circ} \mathrm{C}$ for 60 minutes. After cooling to ambient temperature, the samples obtained were designated 'treated raw cocoons' and 'treated processed cocoons.

\section{Differential scanning calorimetry (DSC)}

Differential scanning calorimetry was used on cocoon fragments 
(total mass of $1,800 \mathrm{mg}$ raw cocoon and $1,600 \mathrm{mg}$ processed cocoon). The samples were placed on hermetic aluminum supports. DSC curves were obtained in a Shimadzu DSC-60 differential scanning calorimeter. Heat was applied at a rate of $10{ }^{\circ} \mathrm{C} \mathrm{min}^{-1}$, over a temperature range of 25 to $300^{\circ} \mathrm{C}$. A gas flow rate of $50 \mathrm{~mL} \mathrm{~min}{ }^{-1}$ was used in a nitrogen atmosphere.

\section{Spectroscopic characterization}

For Raman measurements, the silk cocoons were mounted on glass microscope slides with the aid of metal claws. The Raman spectra and Optical micrographies of the inner surfaces of the cocoons were obtained using a WITec ${ }^{\circledR}$ Alpha300+ Confocal Raman Microscope System and x50 ZEISS lens at wavelengths of 532 and $785 \mathrm{~nm}$. The laser power focused on the sample was maintained at 7.5 and $10 \mathrm{~mW}$, respectively, measured initially by a power meter equipment positioned after the objective lens. The spectra were collected accumulating for 3 seconds after 10 scans.

All spectral deconvolutions were performed using Origin program $(8.0,2007)$. A number of components and the generation of a reasonable fit were assumed in the process, where each component demonstrates the dependence of the treatment performed on the sample through the change in observed relative intensity. A Gaussian function was used and control over parameters (positions and bandwidth) was not performed, and small differences in positions and bandwidths were tolerated.

\section{RESULTS AND DISCUSSION}

Based on the possibility that moderate heating of the silk cocoon could cause some disruptions in the molecular organization of the fibers, the study initially focused on the thermal events that could occur as a result of changes induced by heat treatment.

Figure 1 shows the DSC curves for the raw and processed cocoons. At temperatures of 30 to $150{ }^{\circ} \mathrm{C}$, both curves show an endothermic process characteristic of water vaporization. However, the curve is broadened, probably evidencing a strong interaction between the water molecules and the silk molecules. At temperatures above $326^{\circ} \mathrm{C}$, an exothermal process related to degradation occurs in both kinds of cocoon. The behavior observed in the DSC curves for raw and processed cocoons is similar to that observed by Malay et al. ${ }^{12}$ and Wang et al. ${ }^{13}$ working on the silk fibers of $B$. mori cocoons.

Figure 2 shows the images of the cocoons obtained under the confocal microscope during and after laser irradiation. Figure 2(a) shows silk filaments organized in layers and in some regions the fibers are interlaced to form irregular structures (circled region) unifying the filaments. These structures are probably due to the formation of sericin, as characterized by Hang et al. ${ }^{14}$ and Jin \& Kaplan. ${ }^{6}$
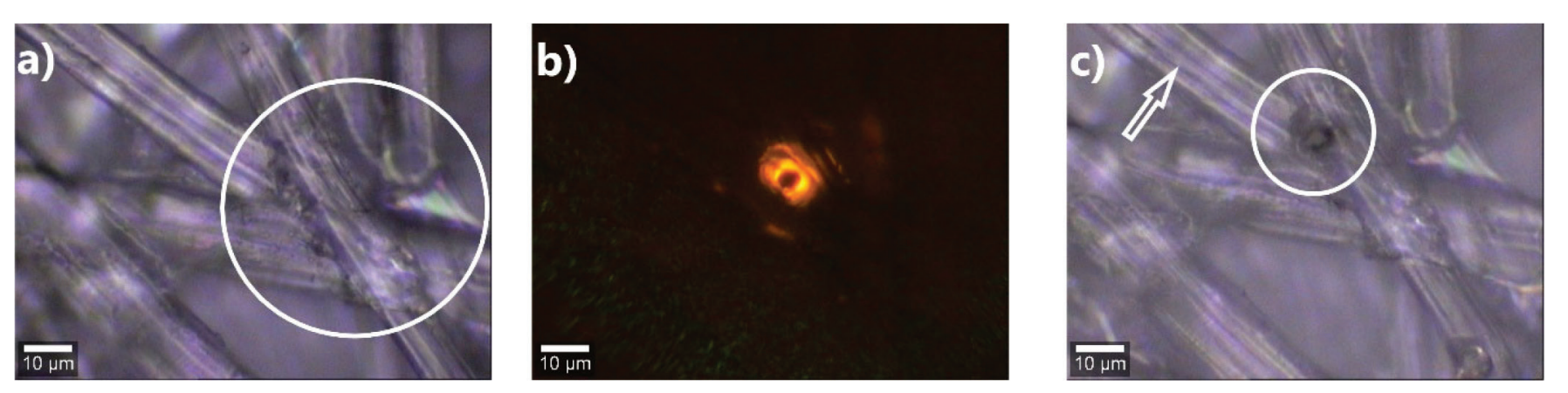

Figure 2. Optical micrographies of the cocoon surface (a), with laser irradiation at $532 \mathrm{~nm}$ (b) and after laser irradiation at $532 \mathrm{~nm}$ (c). A confocal microscope

was used with a X50 lens

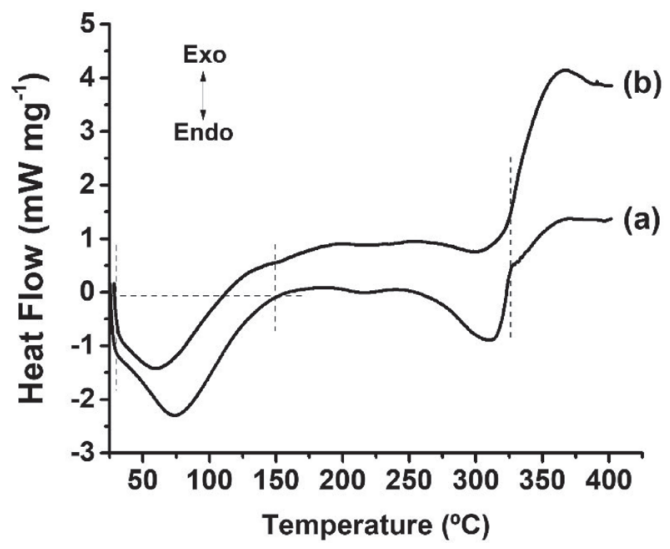

Figure 1. DSC curves: (a) raw cocoon; (b) processed cocoon

Figure 2(b) shows the images obtained with laser irradiation at $532 \mathrm{~nm}$. The fluorescence effect can be observed in the regions of these irregular structures. After laser irradiation was switched off (Figure 2c), there is some visible burning of the material in this region (circled). In contrast, the effect of the radiation in another region of the fiber (indicated by an arrow) at the same laser power did not cause burning. These regions are well defined in the samples and the spectra were obtained in three regions of the fiber and compared, presenting data reproducibility and no sign of sample deterioration and spectral change were observed under these experimental conditions.

Raman spectra at $532 \mathrm{~nm}$ were then obtained for fibers not in the irregular regions in order to study the components of the material structured more uniformly.

Figure 3 shows the Raman spectra for the raw and processed cocoons as received (before heat treatment) and after heating in an oven at 80 and $125^{\circ} \mathrm{C}$ for 60 minutes. The bands at $1676,1559 / 1570$ and $1238 \mathrm{~cm}^{-1}$ were attributed respectively to amide I, II and III, related to the different contributions of $\mathrm{C}=\mathrm{O}$ stretching, $\mathrm{N}-\mathrm{H}$ angular deformation in the plane and $\mathrm{C}-\mathrm{N}$ stretching of the polypeptide chains in the primary structure of the cocoon. ${ }^{15}$

Comparing the initial spectrum of the raw cocoon (Figure $3 \mathrm{Ia}$ ) as the processed cocoon spectrum (Figure 3 IIa) were observed some significant differences in the relative intensities of the bands. Considering that the processed cocoon has previously been thermally treated in drying ovens, this material is likely to have a stabilized amount of sericin, but to a lesser extent than the raw cocoon.

It was not possible to obtain the characteristic Raman spectrum of sericin, because in a region where it accumulates in the cocoon is deteriorated by laser action (Figure 2a and 2c). However, no sign of sample deterioration or spectral change were observed in the fiber region, where sericin possibly should be forming a more stable thin layer on fibroin fibers. As the spectra obtained at $532 \mathrm{~nm}$ show little penetration of the laser in this layer, it should cause differences in 
I)

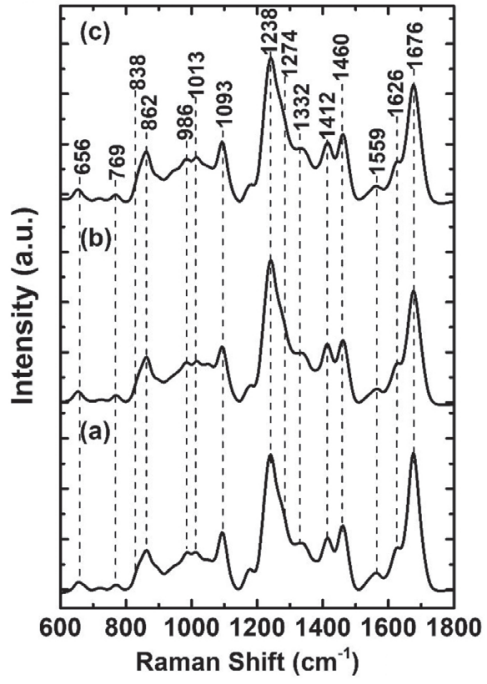

II)

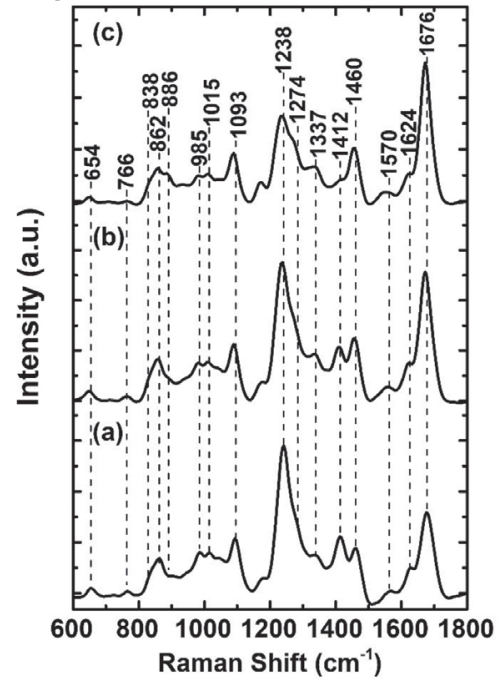

Figure 3. Raman spectra of the surfaces of I) raw cocoon and II) processed cocoon in the $600-1800 \mathrm{~cm}^{-1}$ region; (a) without heating; (b) oven-dried at $80{ }^{\circ} \mathrm{C}$; and (c) oven-dried at $125^{\circ} \mathrm{C}$ for 60 minutes, at excitation of $532 \mathrm{~nm}$

the intensities of the observed bands, e.g. at 1238, 1412, 1460 and $1676 \mathrm{~cm}^{-1}$

The Raman spectra of the raw cocoon (Figure 3I) show that, as the drying temperature is increased, neither of the two temperatures induced spectral changes compared to the cocoon without heat treatment. However, the spectra of the processed cocoon (Figure 3II) show that as the drying temperature increases, there is a drop in the intensity of the band at $1412 \mathrm{~cm}^{-1}$, related to $\mathrm{OH}$ deformation of the serine in the sericin, ${ }^{16}$ and an increase in the intensity of the band at $1460 \mathrm{~cm}^{-1}$ attributed to the angular deformation of $\mathrm{CH}_{3}$ in the poly(alanine) and angular deformation in the plane of $\mathrm{CH}_{2}$ in the poly(alanine-glycine). ${ }^{17-19}$ The images obtained by confocal microscopy show that further drying after reaching $80^{\circ} \mathrm{C}$ results in the formation of sericin particles on the surface of the fibroin filaments. This effect was less marked in raw cocoon samples, possibly because of the higher quantity of sericin still present in the material.

Furthermore, it was also possible to observe a slight broadening of the band at $1238 \mathrm{~cm}^{-1}$, which could indicate that structural disruption is occurring as the temperature increases. According to Monti et al.,$^{20}$ the temperature and drying rate play an important role in destabilizing the molecular structure of the silk secondary structure, i.e. temperature can be considered a key parameter in the disruption of this structure initially present in the silk fibroin. According to Monti et al., ${ }^{16,21}$ the bands at 1238 and $1093 \mathrm{~cm}^{-1}$ are related to $\beta$-sheet conformation in B. mori silk. Furthermore, the frequency at $1274 \mathrm{~cm}^{-1}$ is also related to the presence of $\alpha$-helix conformation.

With the aim of monitoring the effect of structural disruption in the cocoons as the temperature increases (Figure 4), the Raman spectra were deconvoluted over the $1150-1430 \mathrm{~cm}^{-1}$ region.

The deconvoluted spectra show that the intensities of bands at $1274 \mathrm{~cm}^{-1}$ increase compared to intensities at $1238 \mathrm{~cm}^{-1}$, evaluated using $\mathrm{I}_{(1238)} / \mathrm{I}_{(1274)}$ intensity ratios, as shown in Table 1.

For raw cocoon the intensity ratio fell from 2.4 to 1.7 and for processed cocoon from 2.9 to 1.5 for untreated and oven-dried materials respectively. This ratio shows that there was a drop in $\beta$-sheet conformation compared to $\alpha$-helix conformation, resulting in structural disruption as the temperature increased.

The $I_{(1093)} / I_{(1274)}$ band intensity ratios were also evaluated, with similar results.

Bearing in mind the complex structural arrangement of the polypeptide chains and the amino acid residues of the side chains,
Table 1. Intensity ratios $I_{(1238)} / I_{(1274)}$ and $I_{(1093)} / I_{(1274)}$ for raw and processed cocoons, at $532 \mathrm{~nm}$

\begin{tabular}{lccc}
\hline Raw cocoon & No heat treatment & $80^{\circ} \mathrm{C}$ & $125^{\circ} \mathrm{C}$ \\
\hline $\mathrm{I}_{(1238)} / \mathrm{I}_{(1274)}$ & 2.4 & 2.2 & 1.7 \\
$\mathrm{I}_{(1093)} / \mathrm{I}_{(1274)}$ & 1.2 & 1.0 & 0.9 \\
\hline Processed cocoon & & & \\
\hline $\mathrm{I}_{(1238)} / \mathrm{I}_{(1274)}$ & 2.9 & 1.9 & 1.5 \\
$\mathrm{I}_{(1093)} / \mathrm{I}_{(1274)}$ & 1.2 & 1.0 & 1.1 \\
\hline
\end{tabular}

Raman spectra were also obtained at $785 \mathrm{~nm}$ in order to verify whether varying the excitation radiation induced any change.

Figure 5 compares the Raman spectra for the raw and processed cocoons as received (no subsequent heat treatment) at 532 and $785 \mathrm{~nm}$.

Comparing the spectra at $785 \mathrm{~nm}$, there are bands at 719, 885, 931 and $1036 \mathrm{~cm}^{-1}$, characteristic of the polypeptide chains present in the primary cocoon structure (silk fibroin). ${ }^{17,21-24}$ In addition, there is an increase in the intensities of bands at 648/654, 764/766, 833, 858/859, $981,1008,1167$ and $1619 / 1627 \mathrm{~cm}^{-1}$, related to the vibrations of the silk fibroin amino acid side chains. ${ }^{17,18,21}$

As reported by Asakura et al. ${ }^{25}$ the constitution of the amorphous residual sequences of tyrosine present in the silk cocoons could, for the most part, be due to distorted contours of $\beta$-turns and $\beta$-sheets, introducing a random element into the fibroin skeleton. Thus, in the spectra obtained, deconvoluting amide I bands helped to verify whether or not the cocoons were identical at molecular level.

This study was based on the work of Lefèvre et al., ${ }^{11}$ who, by breaking down this band, found frequencies near at 1654, 1670, $1684 / 1694 \mathrm{~cm}^{-1}$, respectively attributed to the $\alpha$-helix, $\beta$-sheet and $\beta$-turn structures.

Raman spectra at $785 \mathrm{~nm}$ (results not shown) were obtained for the surfaces of the raw and processed cocoons as received (no subsequent heat treatment) and oven-dried at 80 and $125^{\circ} \mathrm{C}$ for 60 minutes.

Figure 6 shows the deconvoluted Raman spectra obtained from the aforementioned samples in the $1629-1721 \mathrm{~cm}^{-1}$ region. These spectra were used to evaluate deconvoluted spectra intensity ratios $\mathrm{I}_{(1670)} / \mathrm{I}_{(1654)}, \mathrm{I}_{(1670)} / \mathrm{I}_{(1684)}$ and $\mathrm{I}_{(1670)} / \mathrm{I}_{(1694)}$. 
a)

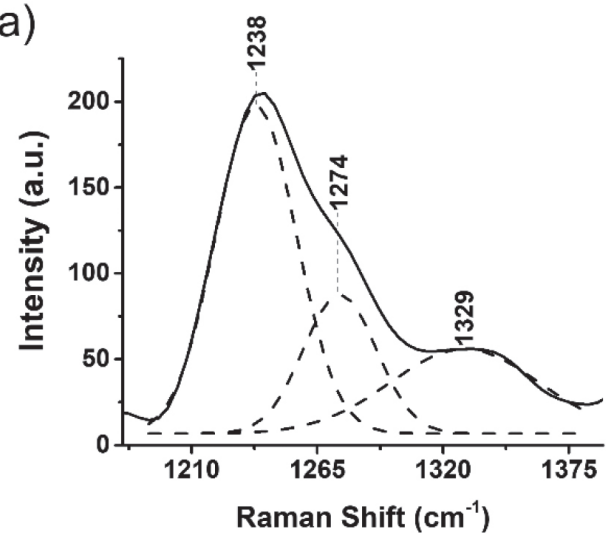

c)

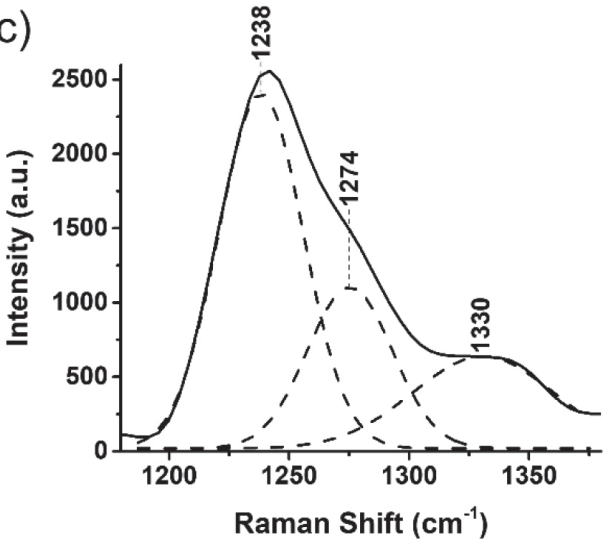

e)

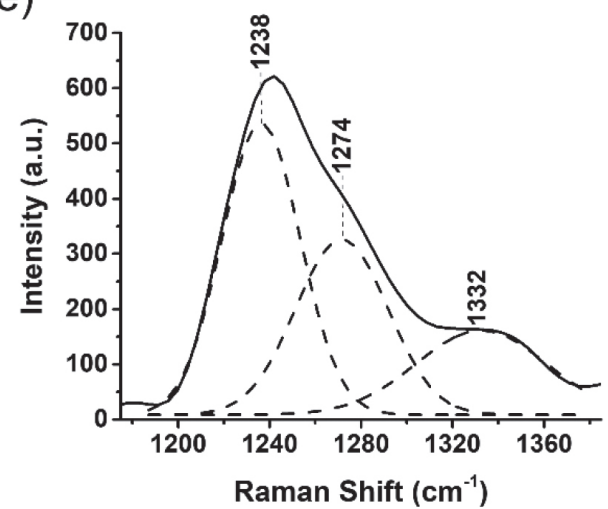

b)

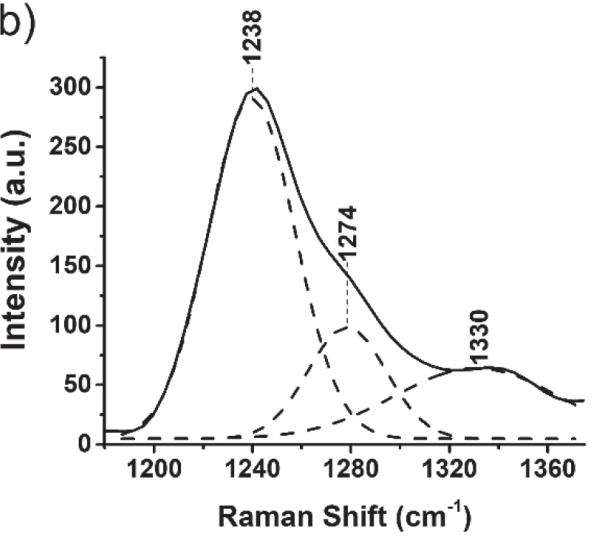

d)

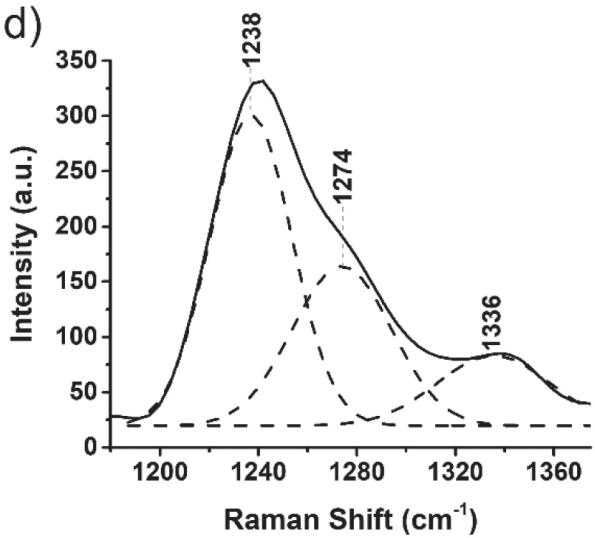

f)

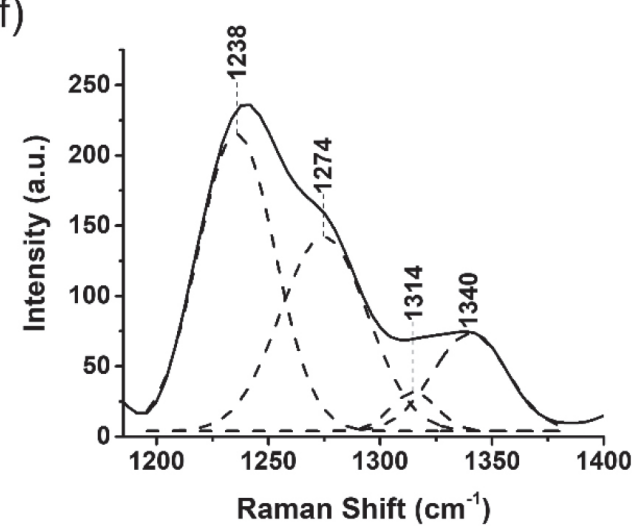

Figure 4. Deconvoluted Raman spectra at $532 \mathrm{~nm}$ in the 1175-1390 $\mathrm{cm}^{-1}$ region for raw cocoon: (a) no heat treatment, (c) oven-dried at $80^{\circ} \mathrm{C}$, (e) oven-dried at $125^{\circ} \mathrm{C}$; and for processed cocoon: (b) no heat treatment, (d) oven-dried at $80^{\circ} \mathrm{C}$, ( $f$ ) oven-dried at $125^{\circ} \mathrm{C}$
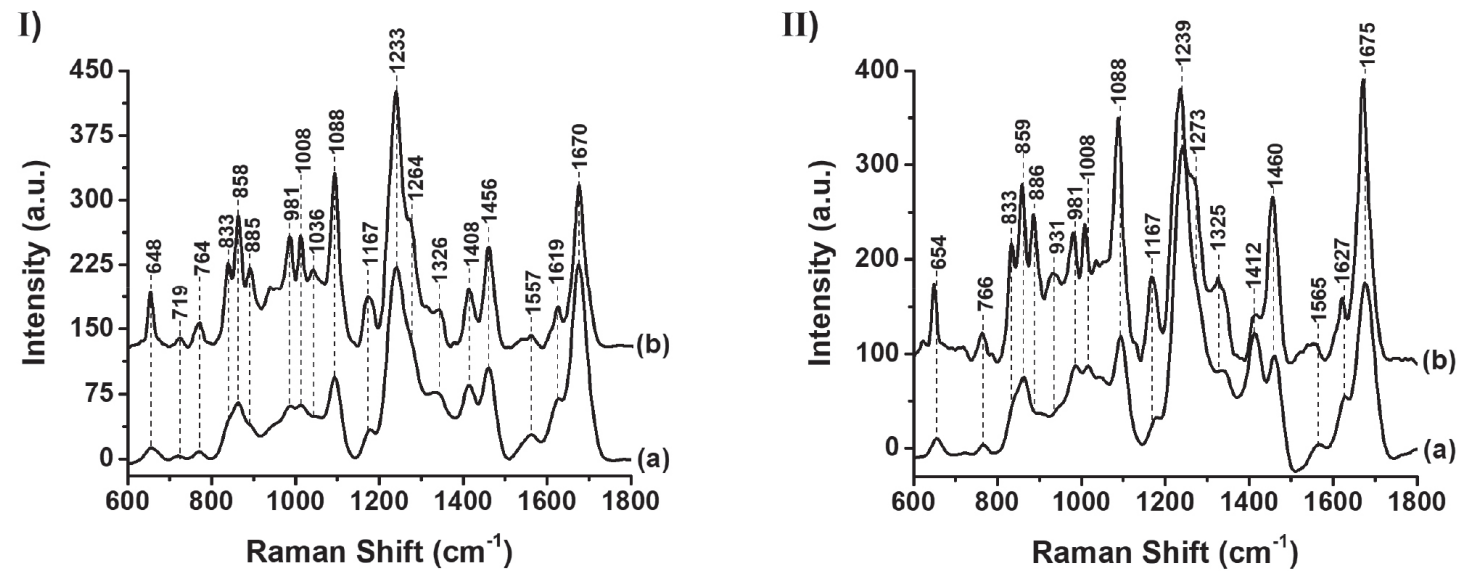

Figure 5. Raman spectra of raw cocoon I) and processed cocoon II) in the 600-1800 $\mathrm{cm}^{-1}$ region, at (a) 532 and (b) $785 \mathrm{~nm}$ 
a)

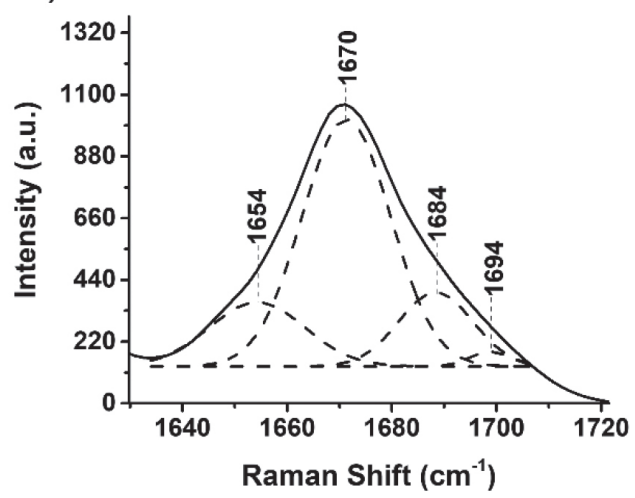

C)

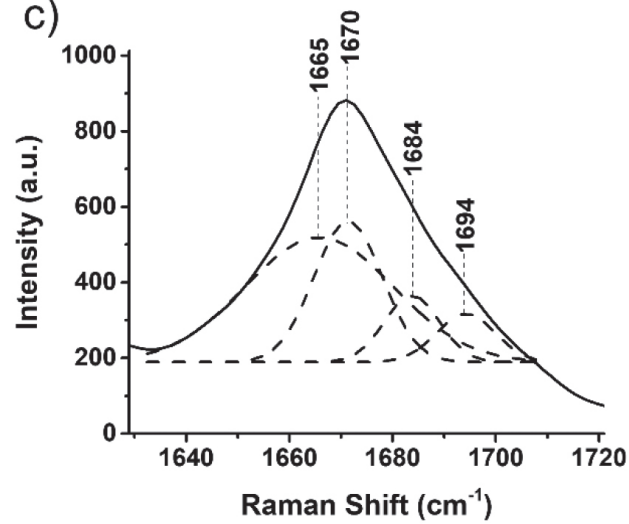

e)

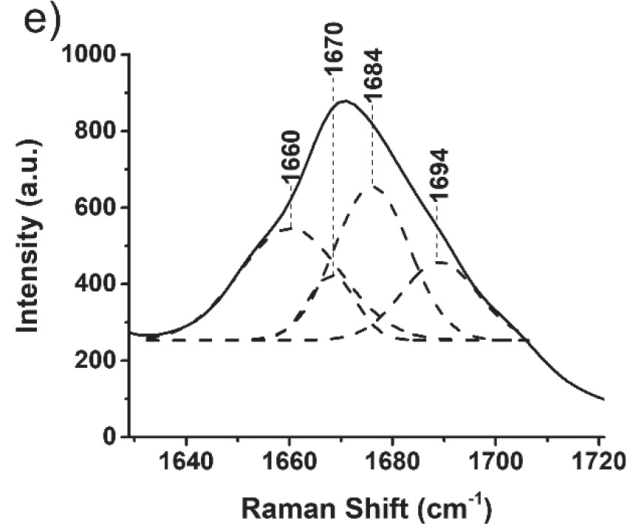

b)

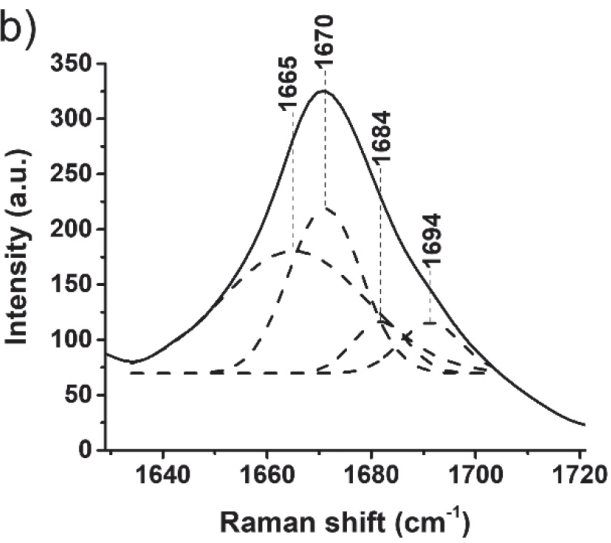

d)

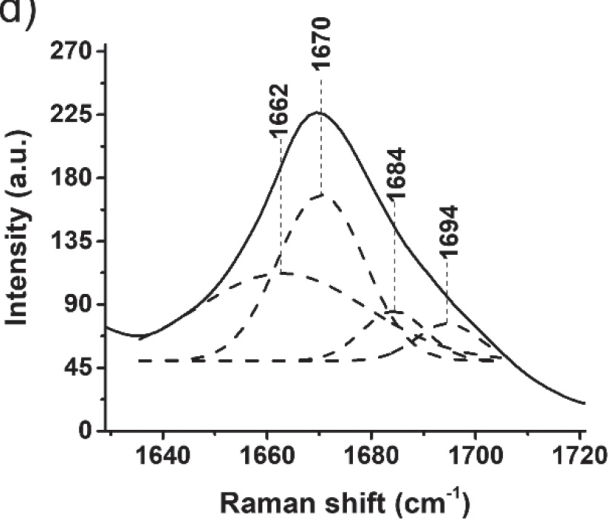

f)

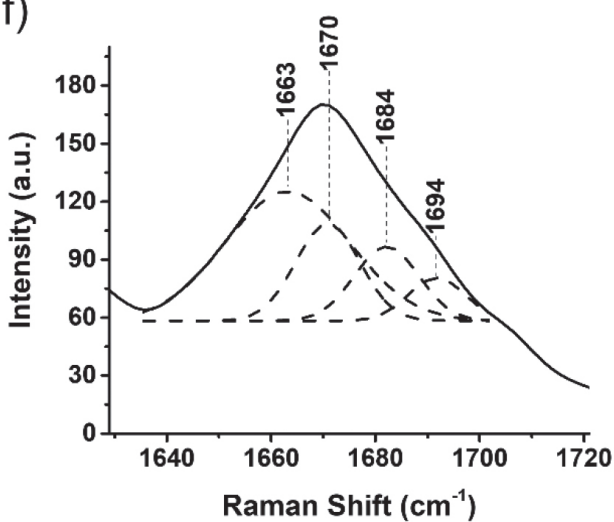

Figure 6. Deconvoluted Raman spectra at $785 \mathrm{~nm}$ in the 1629-1720 $\mathrm{cm}^{-1}$ region for raw cocoon: (a) no heat treatment, (c) oven-dried at $80{ }^{\circ} \mathrm{C}$, (e) oven-dried at $125^{\circ} \mathrm{C}$; processed cocoon (b) no heat treatment, (d) oven-dried at $80^{\circ} \mathrm{C}$, (f) oven-dried at $125^{\circ} \mathrm{C}$

The deconvoluted spectra show that the intensities of bands at 1654,1684 and $1694 \mathrm{~cm}^{-1}$ increase compared to the intensity of the band at $1670 \mathrm{~cm}^{-1}$ (see Table 2).

For raw cocoon, the $\mathrm{I}_{(1670)} / \mathrm{I}_{(1654)}$ intensity ratio fell from 3.9 to 0.6 , and for processed cocoon from 1.3 to 0.8 , comparing the materials with no heat treatment and those oven-dried. This ratio shows that there was a drop in $\beta$-sheet conformation compared to $\alpha$-helix conformation, evidence that structural disruption is aggravated by increased temperature, as already confirmed by the spectra at $532 \mathrm{~nm}$.

It was also observed that in all the deconvoluted Raman spectra (Figure $6 \mathrm{c}-\mathrm{e}$ ) and in the heat treatment processed cocoon spectrum (Figure $6 \mathrm{~b}$ ), the structural disorder promoted a broadening of the characteristic band of the $\alpha$-helix conformation. This fact suggests a greater distortion/degeneration of this component in the material with increasing temperature.

For raw cocoon, intensity ratios $\mathrm{I}_{(1670)} / \mathrm{I}_{(1684)}$ and $\mathrm{I}_{(1670)} / \mathrm{I}_{(1694)}$ fell
Table 2. Intensity ratios $I_{(1670)} / I_{(1654)}, I_{(1670)} / I_{(1684)}$ and $I_{(1670)} / I_{(1694)}$ for raw and processed cocoons at $785 \mathrm{~nm}$

\begin{tabular}{lccc}
\hline Raw cocoon & No heat treatment & $80^{\circ} \mathrm{C}$ & $125^{\circ} \mathrm{C}$ \\
\hline $\mathrm{I}_{(1670)} / \mathrm{I}_{(1654)}$ & 3.9 & 1.1 & 0.6 \\
$\mathrm{I}_{(1670)} / \mathrm{I}_{(1684)}$ & 3.3 & 2.1 & 0.4 \\
$\mathrm{I}_{(1670)} / \mathrm{I}_{(1694)}$ & 16.9 & 2.9 & 0.8 \\
\hline Processed cocoon & & & \\
\hline $\mathrm{I}_{(1670)} / \mathrm{I}_{(1654)}$ & 1.3 & 1.9 & 0.8 \\
$\mathrm{I}_{(1670)} / \mathrm{I}_{(1684)}$ & 3.2 & 3.4 & 1.3 \\
$\mathrm{I}_{(1670)} / \mathrm{I}_{(1694)}$ & 3.2 & 4.5 & 2.3 \\
\hline
\end{tabular}

respectively from 3.3 to 0.4 and 16.9 to 0.8 , and for processed cocoon from 3.2 to 1.3 and 3.2 to 2.3 , comparing the materials with no heat 
treatment and those oven-dried. These results show that there is a drop in $\beta$-sheet conformation compared to $\beta$-turn conformation, possibly due to the transition between these structures with increased temperature.

As verified at both wavelengths (532 and $785 \mathrm{~nm}$ ), the intensity ratios drop as the temperature is increased. Therefore, as reported by Jaramillo-Quiceno et al. ${ }^{26}$ it is likely that heat treating silk fibers at moderate temperatures results in a disruption of molecular alignment concentrated in the amorphous regions, also affecting the crystalline structures of the $\beta$-sheet, which are gradually converted into random structures.

\section{CONCLUSION}

The Raman spectra in the region of the frequencies attributed to amide I and III of the silk fibroin polypeptide chains show a correlation between the intensity ratios of deconvoluted bands in spectra at 532 and $785 \mathrm{~nm}$.

It can be stated that there is a drop in $\beta$-sheet conformation compared to $\alpha$-helix conformation, and a drop in $\beta$-sheet conformation compared to $\beta$-turn conformation due to the transitioning of these structure as the temperature is increased.

Thus, this study of raw and processed cocoons shows that the temperature range evaluated by DSC plays a crucial role in impacting the silk fiber secondary structures of cocoons. The intensity ratios of bands obtained by Raman spectroscopy provide a means of rapidly evaluating the molecular conformation of silk fibers, which could be useful for controlling the properties of these materials.

\section{ACKNOWLEDGMENTS}

We would like to express our posthumous tribute to Prof. Hans Stammreich, on the occasion of the $50^{\text {th }}$ anniversary of his death occurred in March 1969. This study was funded by the Parana State Government under the SETI project (Seda: O fio que transforma).

\section{REFERENCES}

1. Morin, A.; Alam, P.; Mater. Sci. Eng., C 2016, 65, 215.

2. Jo, Y. N.; Um, I. C.; Int. J. Biol. Macromol. 2015, 78, 287.

3. Partlow, B. P.; Tabatabai, A. P.; Leisk, G. G.; Cebe, P.; Blair, D. L.; Kaplan, D. L.; Macromol. Biosci. 2016, 16, 666.
4. Cao, T-T.; Zhang, Y-Q.; Mater. Sci. Eng., C 2016, 61, 940.

5. Zhang, Y. Q.; Tao, M. L.; Shen, W. D.; Zhou, Y. Z.; Ding, Y.; Ma, Y.; Zhou, W. L.; Biomaterials 2004, 25, 3751.

6. Jin, H-J.; Kaplan, D. L.; Nature 2003, 424, 1057.

7. Altman, G. H.; Diaz, F.; Jakuba, C.; Calabro, T.; Horan, R. L.; Chen, J.; Lu, H.; Richmond, J.; Kaplan, D.L.; Biomaterials 2003, 24, 401.

8. Kumar, S.; Singh, S. K.; Part. Sci. Technol. 2016, 35, 304.

9. Sashina, E. S.; Bochek, A. M.; Novoselov, N.P.; Kirichenko, D. A.; Russ. J. Appl. Chem. 2006, 79, 869.

10. Brändén, C-I.; Tooze, J.; Introduction to Protein Structure, $2^{\text {nd }}$ ed., Garland Science: New York, 1999.

11. Lefèvre, T.; Rousseau, M-E.; Pézolet, M.; Biophys. J. 2007, 92, 2885.

12. Malay, A. D.; Sato, R.; Yazawa, K.; Watanabe, H.; Ifuku, N.; Masunaga, H.; Hikima, T.; Guan, J.; Mandal, B. B.; Damrongsakkul, S.; Numata, K.; Sci. Rep. 2016, 6, 1.

13. Wang, T.; Chena, L.; Du, L.; Shen, T.; Li, F.; Huang, L.; Li, Z.; Wu, D.; Mater. Des. 2017, 134, 132.

14. Hang, Y.; Zhang, Y.; Jin, Y.; Shao, H.; Hu, X.; Int. J. Biol. Macromol. 2012, 51, 980 .

15. Arêas, E. P. G.; Kawano, Y.; Quim. Nova 1991, 14, 31

16. Monti, P.; Freddi, G.; Arosio, C.; Tsukada, M.; Arai, T; Taddei, P.; J. Mol. Struct. 2007, 202, 834.

17. Preghenella, M.; Pezzotti, G.; Migliaresi, C.; J. Raman Spectrosc. 2007, $38,522$.

18. Rousseau, M-E.; Lefèvre, T.; Beaulieu, L.; Asakura, T.; Pézolet, M.; Biomacromolecules 2004, 5, 2247.

19. Shao, J.; Zheng, J.; Liu, J.; Carr, C. M.; J. Appl. Polym. Sci. 2005, 96 , 1999.

20. Monti, P.; Freddi, G.; Bertoluzza, A.; Kasai, N.; Tsukada, M.; J. Raman Spectrosc. 1998, 29, 297.

21. Monti, P.; Taddei, P.; Freddi, G.; Asakura, T.; Tsukada, M.; J. Raman Spectrosc. 2001, 32, 103.

22. Edwards, H. G. M.; Farwell, D. W.; J. Raman Spectrosc. 1995, 26, 901.

23. Taddei, P.; Chiono, V.; Anghileri, A.; Vozzi, G.; Freddi, G.; Ciardelli, G.; Macromol. Biosci. 2013, 13, 1492.

24. Colomban, P.; Dinh, H. M.; Riand, J.; Prinsloo, L. C.; Mauchamp, M.; J. Raman Spectrosc. 2008, 39, 1749.

25. Asakura, T.; Yao, J.; Yamane, M.; Umemura, K.; Ulrich, A. S.; J. Am. Chem. Soc. 2002, 124, 8794.

26. Jaramillo-Quiceno, N.; Álvarez-López, C.; Restrepo-Osorio, A.; Procedia Eng. 2017, 200, 384.

FAPESP helped in meeting the publication costs of the article 